\title{
APORTES TEÓRICOS PARA ANÁLISE POLÍTICA DA UNIVERSIDADE
}

\author{
Roseana Costa Leite*
}

RESUMO: Dada a centralidade das instituições educativas de ensino superior no processo de globalização e a emergência de novos conflitos no interior das mesmas, apresenta-se um estudo que constrói uma proposta teórica multidimensional, baseada nas teorias da sociologia política, para análise dos processos políticos da educação superior. Tal proposta integra processos e níveis das teorias sobre o Estado e o sistema político, teorias sociológicas da educação e teorias do poder em suas dimensões instrumental, de controle de agendas e de construção ideológica, todas centradas na análise do conflito e do político. O estudo reconhece que as organizações de educação são espaços políticos em que se confrontam visões e projetos alternativos e que os conflitos giram em torno de temáticas centrais, que podem ser sintetizadas em: acesso, uso social do conhecimento, destinação de recursos, a natureza das profissões e das disciplinas acadêmicas e a característica do trabalho acadêmico.

Palavras-chave: Universidade; Política; Autonomia; Estado; Poder.

\section{THEORETICAL CONTRIBUTIONS FOR THE POLITICAL ANALYSE OF THE UNIVERSITY}

ABSTRACT: Regarding the centrality of higher education institutions in the globalization process and the emergency of new conflicts inside the same, this article introduces itself as a study that builds a multidimensional theoretical proposal, based on the social political theories, to analyze the higher education political process. The study acknowledges educational institutions as political spaces in which different conceptions and alternative projects are confronted and main conflicts spin around some central themes, such as: access, social use of knowledge, resource allotment, professional and academics characteristics.

Keywords: University; Politic; Autonomy; State; Power.

\footnotetext{
* Doutora em Administração Escolar pela Faculdade de Educação da Universidade de São Paulo (USP) e Professora Assistente da Universidade Estadual Paulista Júlio de Mesquita Filho (UNESP). E-mail: rocleite@uol.com.br
} 


\section{Introdução}

Com a intenção de desenvolver uma investigação sobre a temática da autonomia universitária, nossa preocupação voltou-se para uma construção teórica que permitisse uma análise política da universidade. Entre a bibliografia levantada, encontramos alguns autores que se dedicam ao assunto e oferecem uma proposta teórica para enfrentar a questão; pela longa trajetória de estudos que dois desses autores dedicam à análise política da universidade, que se desdobram na reflexão de diversos pontos e autores, e pela síntese importante que formulam do debate, pareceu-nos interessante discutir os aportes teóricos que propõem. Cabe lembrar que esses autores, Imanol Ordorika Sacristan, do Instituto de Investigações Econômicas da UNAM, e Brian Pusser, do Centro para o Estudo da Educação Superior da Universidade de Virginia, desenvolvem, desde há tempos, uma pareceria nos estudos e reflexões sobre os usos políticos da educação superior.

\section{A politicidade da universidade}

Ordorika Sacristan (2001) afirma que os processos políticos das instituições de educação superior, um dos espaços mais politizados da sociedade, tornam-se relevantes dada a centralidade das instituições educativas no mundo globalizado. Apesar da repolitização universitária, ou seja, da emergência de novos conflitos, como a tensão entre governos e instituições sobre o financiamento e as novas dinâmicas políticas nos órgãos, a tendência dos estudos sobre os problemas políticos da educação superior, desde os anos 1970, não foi revertida.

Para superar a ausência ou o mau uso de teorias das ciências sociais, propõe construir um marco teórico multidimensional, utilizando as teorias da sociologia política, para a análise dos processos políticos da educação superior. Esse marco se funda nas teorias de Estado, teorias sociológicas sobre a educação, teorias sobre a educação superior e teorias sobre o poder e a disputa política: a pretensão é a de inter-relacionar essas diferentes propostas de forma coerente.

A partir da literatura existente sobre os problemas de administração e gestão na educação, o autor propõe quatro dimensões de análise, 
a partir de dois eixos: organizacional/funcional/interpretativo e social/funcional/interpretativo. Acrescenta que a maioria das análises sobre a administração da educação superior se localiza no aspecto organizacional/funcional, são perspectivas funcionalistas enfocadas nas estruturas de gestão ou em processos e mecanismos de decisão e enfatizam os objetivos, fronteiras, relações com os meios, tecnologias e trabalho das organizações de educação superior. Outros estudos denominados funcionalistas sociais enfatizam as relações entre instituições e seu entorno, ou seja, as organizações universitárias, suas estruturas e processos administrativos enquanto determinados por fatores externos; explicam os processos de mudança na educação superior como respostas à dinâmica dos mercados ou com o propósito de incrementar suas possibilidades de sobreviver em uma situação em que os recursos são escassos. Sem dúvida, os mercados e o acesso a recursos são relevantes para explicar as mudanças na educação superior, entretanto essas análises não conseguem explicar por que as universidades têm tido respostas limitadas frente a demandas propostas pelo mercado econômico ou trabalhista e mantêm uma estrutura arcaica, organizada em torno de disciplinas acadêmicas e escolas profissionais. Para ele, ainda, a dependência de recursos é insuficiente para explicar decisões nas universidades que limitam o acesso a recursos financeiros.

Além das aproximações funcionalistas, desenvolveram-se análises interpretativas que enfatizam o estudo dos processos culturais e de seus significados. As perspectivas culturais se dividem em seus enfoques ao interior ou exterior das instituições de educação. Há estudos que enfocam, a partir das concepções sobre a construção social da realidade, as interações simbólicas e substantivas e os sistemas de crenças essenciais para manter a legitimidade das organizações. Esses teóricos, chamados institucionais, explicam a mudança na educação superior como uma resposta a demandas sociais e culturais. Entretanto, essa vertente analítica não reconhece que os mitos institucionais e as percepções culturais são objeto de disputa e confrontação, ou seja, são moldados por conflitos políticos no âmbito organizacional e social que constituem seu entorno.

Argumenta que é possível superar as brechas existentes entre as teorias funcionalistas e interpretativas em seus enfoques interno e externo. Para isso, é necessário atentar às conexões entre os processos sociais, institucionais e à interação entre eles; também é essencial identificar os objetos de caráter estrutural e os de natureza cultural, além de reconhecer 
que as organizações de educação são espaços políticos em que se confrontam visões e projetos alternativos.

Isso implica a necessidade de incorporar uma reflexão acerca do Estado como um espaço em "que se conectam o estritamente organizacional com o histórico e social, em que se articulam as dimensões estruturais e culturais e em que se condensa a natureza política das instituições de educação superior", para desenvolver uma teoria do conflito na educação superior (p. 81). Sustenta que há uma visão das instituições de educação como organizações politicamente neutras e autônomas, enraizadas na competência profissional e no comportamento racional, em oposição ao Estado como um ente irracional. "Consideram-se as instituições de educação superior como espaços autônomos e independentes de práticas políticas e burocráticas. E ao Estado se percebe como adversário e externo à instituição universitária"2 (2001, p. 81).

Além disso, desconhece-se a existência de relações de poder ou aceita-se que estas só existem nos espaços de tomada de decisões e, ademais, não se vê o Estado como a representação dos interesses da classe econômica no poder.

As visões classistas do Estado não são homogêneas e variam em torno de duas dimensões: o grau de autonomia ou controle do Estado por uma classe capitalista e o peso da estrutura econômica frente à superestrutura no processo de dominação.

Para ele, o conceito de hegemonia abre a possibilidade de analisar o Estado como uma instituição dinâmica, produto da evolução histórica das relações entre grupos e classes confrontadas na sociedade, tanto em nível das relações econômicas quanto no âmbito cultural, com ênfase no desenvolvimento das ideologias dominantes. As organizações de educação superior são instituições do Estado e, portanto, um espaço de confrontação entre as classes.

Existem também diversas perspectivas sobre a educação na sociedade capitalista, que podem se agrupar em três tendências. Primeiro, as visões instrumentais e estruturalistas acerca do Estado, que veem a educação como um mecanismo para a reprodução da sociedade capitalista (Bourdieu e Passeron, Bowles e Gintis, Carnoy). Segundo, as que veem o Estado como um organizador da acumulação capitalista relativamente autônomo, que busca um equilíbrio entre a maximização da acumulação e a busca de legitimidade, e analisam a educação como uma fonte de legitimidade compensatória (Offe, Weiler). 
Em terceiro, estão as perspectivas que trabalham com o conceito de hegemonia e do Estado como espaço em disputa, e admitem duas visões do espaço educativo como cenário de disputa. Uma primeira compreende o confronto no espaço educativo como resultado da resistência à demanda reprodutiva da educação, baseada no desenvolvimento da consciência através do questionamento e da luta pela transformação, e enfatiza o conflito em torno da ideologia (Apple, Freire, Giroux). A segunda perspectiva entende o conflito na educação como produto de demandas contrapostas para incrementar a acumulação de capital, por um lado, e para lograr a igualdade da sociedade, por outro. As disputas se desenvolvem no sistema educativo e no conjunto da sociedade e essa perspectiva enfatiza o estudo do conflito em relação aos propósitos, à administração e aos recursos para a educação (Carnoy e Levin).

$\mathrm{O}$ autor defende que essas concepções da educação como um cenário de conflitos apresenta um marco conceitual para a análise do poder na administração das instituições de educação superior. Nelas as universidades são analisadas como instituições do Estado, ou seja, como espaços de luta e disputa; por conseguinte, sua natureza reprodutiva é questionada, mas como produto de lutas e movimentos sociais, além de ser entendida também como um espaço de igualdade e democratização das relações sociais no conjunto da sociedade.

Argumenta que, além disso, essas teorias em conjunto sustentam os fundamentos para uma teoria política da administração universitária ao: a) permitir estudar as disputas políticas e a distribuição de recursos na educação como confrontações em torno de concepções ideológicas; b) analisar as estruturas e os processos de tomada de decisões na educação como um produto histórico da relação entre grupos dominantes e subalternos; c) explicar as transformações na educação superior como consequência de demandas contrapostas pela reprodução da ideologia e pela capacitação, por um lado, e pela igualdade e a aquisição de consciência, de outro.

Entretanto, as teorias sobre o conflito têm limitações para a compreensão plena da administração nas instituições de ensino superior, principalmente nas relações entre órgãos. Primeiro porque essas teorias desenvolveram-se em referência a estados denominados democráticos, que apresentam características muito particulares; segundo, devido à ausência de uma teoria acerca do processo de disputa política em si 
mesmo. Essas limitações se tornam mais evidentes quando se estudam processos políticos em instituições no contexto de sistemas políticos autoritários ou quando se distinguem as instituições de educação de outras instituições do Estado.

Observa que as disputas políticas nas instituições de educação superior se expressam em torno das seguintes temáticas centrais: acesso, usos sociais do conhecimento (profissionalização, investigação e extensão) e destinação de recursos.

O acesso à educação superior está determinado por intentos de regular a reprodução da força de trabalho e por demandas sociais como mecanismo de ascensão social; tal regulação se baseia em uma ideologia meritocrática que, além do fato de ser totalmente darwinista social, premia atitudes e capacidades da cultura dominante, possuídas pela classe média, mas que não são frequentemente encontradas entre os imigrantes, a classe operária ou os trabalhadores pobres.

Os debates acerca do uso social dos conhecimentos relacionamse à hierarquia e orientação das disciplinas acadêmicas e às profissões, bem como à expansão ou ao controle do acesso de estudantes a programas acadêmicos que têm as taxas mais altas de retorno. Esses debates afetam também a investigação, as políticas científicas e a prioridade de disciplinas mais relacionadas com a produção sobre outras mais relacionadas com as necessidades sociais. Em relação à distribuição de recursos, entende que ela se encontra relacionada às fontes de financiamento, à transferência de custos e aos padrões de gasto em instituições de educação superior.

Além disso, as instituições de educação superior também possuem contradições inerentes relacionadas à natureza das profissões e às disciplinas acadêmicas e às características do trabalho. As profissões e as disciplinas acadêmicas têm dinâmicas e objetivos diferenciados e frequentemente contrapostos; e mesmo no interior das disciplinas e profissões existem diferentes orientações, pensamentos, paradigmas e métodos que também expressam conflitos. O conflito sobre a natureza do trabalho é o produto de dois tipos de atividades diferenciadas, algumas que se podem caracterizar como burocráticas e outras como acadêmicas ou profissionais. É uma caracterização complexa, pois as universidades têm algumas características burocráticas, tais como a divisão do trabalho, a hierarquia administrativa e a estrutura formal, mas não têm outros atributos, como 
uma supervisão do trabalho dos professores e da maioria dos empregados ou regras operativas detalhadas para o desempenho acadêmico.

O trabalho acadêmico e profissional é autônomo e autorregulado e os padrões são estabelecidos por associações profissionais, por isso a autoridade dos profissionais e acadêmicos está baseada no conhecimento especializado, reconhecido institucionalmente, que entra em conflito com a autoridade administrativa, baseada em posições oficiais e numa hierarquia burocrática (BLAU, 1973). Entretanto, adverte o autor, os requisitos administrativos estão produzindo mudanças no trabalho autônomo e autorregulado dos acadêmicos e essa é uma das causas mais importantes do conflito interno nas instituições de educação superior contemporâneas.

Além dos conflitos entre acadêmicos e administradores, outro aspecto a ser analisado refere-se aos estudantes como parte da organização, pois estes participam, de uma maneira ou de outra, são parte dos confrontos internos e contribuem para dar forma à instituição. Outra fonte de conflito incide sobre as características dos trabalhadores manuais e administrativos e seu papel nas instituições, temática em que há poucas investigações.

Para o autor, o desenvolvimento de uma teoria política do conflito na educação superior se baseia na análise das lutas pelo poder, entendido como capacidade para determinar resultados, em três dimensões: a) dos atores, das estruturas e dos processos de tomada de decisões (Dahl, Weber); b) do controle da agenda política (Bachrach y Baratz); c) do processo de produção e incorporação de percepções, cognição e preferências de uma ideologia dominante (Lukes, Gramsci).

Adverte que, na análise do poder, é importante estabelecer a diferença entre as fontes e o exercício do poder. No estudo do exercício do poder (Lukes), os teóricos pluralistas estabeleceram uma equivalência entre o conceito do poder e o de participação nos processos de tomada de decisões. De acordo com a perspectiva pluralista, o poder se centra em resultados, nos êxitos ou fracassos em conseguir aprovar suas iniciativas, ou em vetar as iniciativas de outros, e o poder só está presente quando se tomam decisões sobre temas fundamentais. As perspectivas pluralistas foram criticadas por Bachrach e Baratz, sob o argumento de que o poder tem duas facetas: decisões e não-decisões; pois, a não-decisão é um mecanismo pelo qual temas e demandas específicas podem ser eliminados, na 
medida em que circunscrevem o âmbito das decisões a temas relativamente inofensivos. É o método principal para manter as regras do jogo, "que operam sistemática e consistentemente em benefício de certas pessoas e grupos às custas de outros". Existem várias formas de não se tomar decisões, por exemplo: o uso da força é a forma mais direta, a coerção é a ameaça de exercer sanções negativas (privação) ou positivas (cooptação), para inibir demandas questionadoras, e a invocação de prejuízos existentes, que é o uso de normas, regras ou procedimentos para se desfazer de propostas ameaçantes. A perspectiva pluralista, portanto, oferece limitações, primeiro porque parte do suposto de que a não-tomada de decisões é uma ação individual e não uma expressão de forças coletivas e arranjos sociais. Segundo, supõe também que o poder só se expressa na presença do conflito aberto e não considera o exercício do poder para evitar o conflito por meio de processos que moldam as próprias demandas. Finalmente, supõe que a ausência de impugnações e mal-estar expressados de maneira pública e aberta implica o alcance de um consenso.

A terceira dimensão para a análise do poder incide sobre o nível da hegemonia cultural, que é um processo seletivo de incorporação de interpretações históricas, valores e significados; esses processos de conformação de identidades dominantes são denominados, no caso da educação superior, criação de sagas universitárias, em torno das quais se definem os temas aceitáveis da agenda e se estabelece o exercício do poder.

As três dimensões do estudo do exercício do poder estão relacionadas entre si, embora a distinção analítica abra perspectivas de análise sobre os processos políticos nas instituições de educação superior

O autor tenta, portanto, construir um modelo teórico para a análise dos processos políticos e administrativos das instituições de ensino superior, por meio de conexões entre os diferentes níveis teóricos de quatro componentes. O primeiro nível é o da teoria do Estado, que parte do suposto de que o Estado classista é palco de conflito entre setores dominantes, que perseguem um aumento da acumulação de capital, e subalternos da sociedade, que requerem justiça social, equidade e democracia. É uma luta por hegemonia e pela destinação e distribuição de recursos que se desenvolvem no Estado e em suas instituições.

O segundo nível analisa as organizações de educação superior como instituições do Estado, nas quais o conflito toma formas particulares, pelas demandas da reprodução da ideologia dominante e da força de 
trabalho, bem como pela produção de conhecimentos para gerar incrementos à produtividade e à acumulação; tais demandas se opõem às exigências pela ampliação do acesso, pela expansão da função de mobilidade social da educação e pelo incremento da participação democrática. O conflito se expressa em torno de projetos de reforma educativa.

O terceiro nível prevê a contextualização da competência política da universidade e do Estado em seu conjunto; um sistema político que engloba quatro características: os limites da competência política democrática, a natureza da ideologia dominante, os graus de mobilização e participação política e a natureza da liderança política.

O quarto nível teórico apresenta três dimensões para o estudo dos processos políticos: a dimensão instrumental, que engloba os atores centrais da tomada de decisões, as elites políticas e burocracias; a dimensão de políticas específicas, na qual se inclui o controle sobre as agendas e o desenvolvimento histórico de temas na definição das políticas; e a dimensão hegemônica, que revela a criação e a recriação de culturas dominantes e identidades por meio do processo político.

Para o autor, o estudo da educação superior requer elaborações teóricas que centrem atenção nos processos políticos de gestão e mudança universitária e que partam das análises teóricas desenvolvidas na economia, na sociologia, na política, na história e na psicologia, para possibilitar a coerência interna dos arranjos teóricos e sustentar uma capacidade explicativa.

O modelo proposto questiona o mito da neutralidade política e ideológica das instituições de educação superior, que têm permitido a constituição de um sistema de dominação política que conecta elites e burocracias nas organizações de educação superior com os grupos correspondentes no aparato do Estado. Para o autor, a ruptura desse mito não é simples

nem na ordem analítica nem na consciência dos atores sociais da universidade. Para desentranhar a complexidade das relações políticas e de poder, que se sustenta na ideologia dominante, faz-se necessário um marco conceitual que articule espaços tradicionalmente diferenciados na arbitrária distinção entre o externo e o interno (o organizacional e o social). ${ }^{3}$ (2001, p. 93)

A proposta teórica que desenvolve integra processos e níveis das teorias sobre o Estado e o sistema político, teorias sociológicas da educa- 
ção, teorias do poder, em suas dimensões instrumental, de controle de agendas e de construção ideológica, todas centradas na análise do conflito e do político.

Para ilustrar a formulação teórica exposta, apresentamos, a seguir, uma análise política da Universidade de Virginia realizada por Pusser (2008b), em que ele recupera os elementos ou dimensões propostos por Ordorika Sacristán.

\section{As dimensões políticas da universidade}

Para pensar as práticas políticas da universidade, Pusser (2008b) parte da análise do Estado, no caso o Estado na América do Norte, e, a partir de suas características histórico-políticas, classifica-o em quatro tipos: o federalismo ligado ao estado de direitos; o New Deal correspondente ao estado provedor e regulador; o estado neoliberal, com a desregulação e a privatização; e o estado predador, com o hipercapitalismo e a erosão das instituições (James K. GALBRAITH, 2008).

Examina ainda o Estado, o mercado e a política contemporâneos nos Estados Unidos e levanta alguns pontos centrais, tais como o Estado de segurança, após o 11 de Setembro; a política educativa, cujo eixo central adota o slogan "no child left behind", correspondente à brasileira "nenhuma criança fora da escola"; aponta algumas instituições privadas ou de mercado que direcionam investimentos na educação; e a terceirização e subcontratação aplicada inclusive na política defensiva na guerra contra o Iraque, denominada State Corporate Warriors, por Peter Singer (2003).

Lança um questionamento acerca da possibilidade de estarmos vivendo o fim do sistema de governança neoliberal, baseado em duas declarações. A primeira, do principal historiador financeiro norte-americano, Ron Chernow: "We have the irony of a free-market administration doing things that the most liberal Democratic administration would nerver have been doing in its wildest dreams". A segunda, do ex-chefe antitruste da Comissão Europeia, Mario Monti: "For opponents of free markets in Europe and elsewhere, this is a wonderful opportunity to invoke the American example. They will say that even the standard-bearer of the market economy, The United States, negates its fundamental principles in its behavior". 
Para pensar as relações entre universidades, o Estado e a sociedade civil, o autor oferece mais questionamentos e pergunta, na relação Estado e universidade, quem representa a universidade na disputa com o Estado? Sugere a existência de uma tensão entre a universidade e a sociedade civil e uma disputa entre o Estado e a sociedade civil pela educação superior e também pergunta quem representa a sociedade civil na disputa política com a universidade?

Afirma que, no terreno político, a universidade pode ser compreendida como uma instituição política do Estado, em que ocorrem alianças políticas internas e externas e parece haver uma mudança na sua condição de instituição não-lucrativa. A questão central, para o autor, incide sobre quais interesses estão sendo beneficiados e destaca duas características da universidade contemporânea: estratificação e desigualdade.

Para além do Estado, a universidade pode ser entendida como um espaço público, como um local de grande importância intelectual, cultural e simbólica para a sociedade e para a economia política, de forma geral; representa ainda um espaço de resistência, de crítica e de investigação crítica livre do controle do Estado, dos interesses privados de mercado ou da própria instituição.

Revisita um estudo de Clark (1983) acerca das relações autoritárias no sistema da educação superior, para demonstrar os polos de interesse que disputam influência nos sistemas universitários: o Estado, o mercado e a oligarquia acadêmica. Segundo o triângulo de Clark, as universidades na URSS, na Suécia e na França encontram-se mais vinculadas aos interesses do Estado; na Itália e na Inglaterra, aos interesses da oligarquia acadêmica; e no Canadá, no Japão e nos Estados Unidos, respondem mais aos interesses do mercado. O que abre oportunidade para perguntarmos a que interesses respondem as universidades brasileiras?

A fim de aprofundar sua análise política sobre a universidade, propõe o exame da reestruturação da Universidade de Virginia, Califórnia, instituição na qual trabalha e que passa por uma série de transformações e disputas de poder. Nessas disputas, identifica algumas questões importantes, a revisão da função da universidade pública, o poder das instituições de ensino médio, o poder do mercado, a ação do Estado para o equilíbrio entre o bem público e o privado. Examina ainda a educação superior no estado de Virginia, o número de instituições, de estudantes, o tamanho do sistema de ensino médio e os valores em investimento em 
educação superior no estado, do qual apenas cerca de um quarto vem da esfera pública ou estatal. Observa também um declínio, nos últimos vinte anos, na alocação de verbas públicas para o ensino superior no estado, o controle público do pagamento de taxas escolares para esse nível de ensino, uma crescente disparidade entre estudantes com financiamento para custear seus estudos e estudantes que se autofinanciam, nas principais instituições, e a aspiração da Universidade de Virginia para se tornar a principal universidade pública em financiamento privado no país.

Entre os principais objetivos da reestruturação da Universidade de Virginia encontram-se: para a instituição, a ausência de competitividade, a qualidade e o controle dos recursos; para os empregados, o padrão central do estado; para as decisões institucionais, a autonomia institucional versus a responsabilidade pública pelos resultados; e para os estudantes, a excelência e a acessibilidade. Destaca a centralidade da receita institucional nessa reforma para os dirigentes centrais.

Como desdobramento da política de competição, pergunta se as instituições estão divididas ou unidas e percebe uma transição na administração universitária, na qual a liderança está nas mãos do diretor ou do reitor, com o respectivo aumento das preocupações trabalhistas, e uma preocupação com a prestação de contas dirigida aos estudantes e à mídia.

O estado exige das instituições quatorze condições e cada instituição deve apresentar um plano estratégico para atingir os seguintes objetivos: acesso para a população desassistida; educação que não seja muito cara; educação ligada ao desenvolvimento econômico; processo de acesso a todos para a educação superior; padrões acadêmicos; obtenção de controle crescente sobre taxas e outras receitas públicas, arranjos trabalhistas e procedimentos financeiros; postos de trabalho preservados, mas sem criação de novos postos; uma gestão ligada ao crescimento da autonomia institucional com a respectiva responsabilidade pela prestação de contas; e preservação da acessibilidade de custos aos estudantes.

As lições que podem ser apreendidas da competição política na Universidade de Virginia, segundo o autor, levam à compreensão das universidades públicas e privadas como instituições políticas, locais e instrumento da competição política, e como produtoras dos bens público e privado demandados por grupos de interesse. Permitem ainda verificar a importância da competição, a centralidade da universidade como esfera pública e o Estado como guardião da esfera pública. 


\section{Considerações finais}

Enquanto espaço político da sociedade há uma disputa pela universidade, em que interatuam diferentes projetos, visões e interpretação nas formas de pensar a universidade e fazê-la, o que não permite caracterizá-la simplesmente como uma comunidade ou associação científica em busca da verdade. Entretanto, é forçoso admitir que a universidade é uma instituição distinta de outras, em que as comunidades científicas no exercício do poder decidem o que é verdade e o que não é, o que é aceitável ou não.

A universidade é política e, analiticamente, existem dois grandes âmbitos de disputa, um referente à própria universidade, ou seja, suas disputas internas, e outro à universidade em relação com a sociedade, às disputas externas, lembrando, entretanto, que ambos os níveis se inter-relacionam.

As disputas na universidade ocorrem, basicamente, em três âmbitos, segundo os autores: a) o acesso ou a expansão do sistema público ou particular; b) os usos do conhecimento, que permitem as seguintes indagações: o que se investiga? Qual formação? Para quê? O que faz a universidade? $\mathrm{O}$ que queremos que façam as universidades?; c) os recursos que a ela se destinam, que levantam os seguintes questionamentos: para que área? Por quê? Para quê? Todas referentes às determinações políticas no uso dos recursos.

Em relação às formas de disputas universitárias, os autores encontram duas vertentes principais: a) a condução da universidade a partir de conselhos técnicos-burocráticos, que pode ser caracterizada como autoritária, em um sistema também autoritário, em que a cúpula domina o poder, com uma divisão pouco clara de poderes, com ideologia frouxa, uma legitimidade baseada na meritocracia e nas alianças acadêmicas entre grupos e profissões; além disso, não se joga de maneira aberta e as relações aristocráticas permeiam a universidade; b) as relações externas partem dos grupos no poder com o exterior, pautadas por relações aristocráticas, em que pesam nomes e sobrenomes, e redes internas com prestígio acadêmico.

O grande problema para a análise política da universidade refere-se ao fato de que se nega que haja política na universidade e, ademais, esta não se encontra predeterminada, depende da injunção e das relações 
externas e internas do governo universitário, embora, em última instância, definam temas como os da liberdade de cátedra e autonomia universitária.

Em relação ao tema da autonomia das universidades públicas, sujeitas às relações com o governo, em seus diversos níveis, os autores apontam três dimensões de análise: 1) instrumental, de matriz weberiana, referente à dominação burocrática ou, mais precisamente, às formas de disputa de poder; 2) sobre o controle das agendas, sobre o que se discute e o que não se discute, sobre quem determina os temas a respeito dos quais são tomadas decisões e sobre quais temas não se tomam decisões, o que se constitui em outra forma de disputa de poder; 3) a visão de universidade, a dimensão mais interessante de todas e a que determina as demais, em que se discute o que é e o que deve fazer a universidade, que se refere à questão da hegemonia, de matriz gramsciniana, e se constitui no grande espaço de disputa universitária.

A primeira grande tarefa é reconhecer o caráter político da universidade e lembrar que a disputa pelo poder depende da ação, é sempre dinâmica. A autonomia constitui-se em uma manifestação da relação de força entre o interior e o exterior da universidade, basicamente entre o Estado e a universidade, numa relação complexa em que a capacidade de intervenção e os limites colocam-se em ambos os lados. Entretanto, os grupos empresariais têm melhor se articulado para tratar de definir o que se espera da universidade. O Estado é um espaço de disputa da sociedade e não impõe à universidade o que ela tem de fazer, visto que a universidade não é um aparato de reprodução, mas um espaço de disputa. 


\section{REFERÊNCIAS}

APPLE, Michael W. Cultural and economic reproduction: essays on class, ideology and the state. London, Boston: Routledge \& Kegan Paul, 1982.

BACHRACH, Peter; BARATZ, Morton S. Power and poverty; theory and practice. New York: Oxford University Press, 1970.

BLAU, P. The organizacion of academic work. New York: John Wiley, 1973.

BORDIEU, Pierre; PASSERON, Jean Claude. Reproduction in education, society and culture. London; Beverly Hills: Sage Publications, 1977.

BOWLES, Samuel; GINTIS, Herbert. Schooling in capitalist America: educational reform and the contradictions of economic life. New York: Basic Books, 1976.

CARNOY, Martin. Education as cultural imperialism. New York: D. Mckay Co., 1974.

CARNOY, Martin; LEVIN, Henry M. Schooling and work in the democratic state. Stanford, Calif.: Stanford University Press, 1985.

CLARK, Burton. The higher education system: academic organization in cross-national perspective. Berkeley : University of California Press, 1983.

DAHL, Robert A. Who governs? Democracy and power in an American city. New Haven: Yale University Press, 1966.

FREIRE, Paulo. Pedagogy of the oppressed. New York: Herder and Herder, 1970.

GALBRAITH, James K. The Predator State: hyper-capitalism and the erosion of institutions. New York; Free Press, 2008.

GIROUX, Henry A. Ideology, culture and the process of schooling. Philadelphia, Pa: Temple University Press, 1981.

GRAMSCI, Antonio. Seletions from the prison notebooks of Antonio Gramsci. London: Lawrence \& Wishart, 1971.

LUKES, Steven. Power: a radical view. London; New York: Macmillan, 1974.

OFFE, Claus. The theory of the Capitalism State and the Problem of Policy Formation. Pp. xiv, 450. In: Stress and contradiction in modern capitalism: public policy and the theory of the State. L.N. Lindberg, Lexington, Mass.: Lexington Books, 1975.

PUSSER, Brian. The political uses of the university. Conferência magistral apresentada no II Curso Universidad Pública en México de Hoy, módulo 3, 26 de setembro de 2008 (b).

QUEM É O AUTOR? The State, the market and the institutional estate: revisiting contemporary authority relations in higher education. In: SMART, J.C. Higher education: handbook of theory and research, Springer Science + Business Media, v. XXIII, p. 105-139, 2008(a).

SACRISTÁN. I.O. Aproximaciones teóricas para el análisis del conflicto y el poder en la educación superior. Perfiles Educativos, v. XXXIII, n. 91, p. 77-96, 2001.

WEBER, Max; MILLS, C. Wright; GERTH, Hans H. From Max Weber: essays in sociology. New York: Oxford University Press, 1946.

WEILER, Hans N. Legalization, Expertise, and Participacion: Strategies of Compensantory Legitimation in Educational Policy. Comparative Educational Review, v. 27, n. 2, p. 259-77, 1983. 


\section{NOTAS}

1 Tradução minha.

2 Tradução minha.

3 Tradução minha.

Recebido: 07/05/2010

Aprovado: 15/09/2010

Contato:

Universidade Estadual Paulista Júlio de Mesquita Filho Faculdade de Ciências e Letras de Araraquara

Departamento de Ciências da Educação

Rodovia Araraquara-Jaú, Km 1

Caixa Postal 174

Araraquara - SP

CEP 14800-901 